\title{
Aberrantly expressed genes and miRNAs in human hypopharyngeal squamous cell carcinoma based on RNA-sequencing analysis
}

\author{
HU LI ${ }^{1}$, FULING WANG ${ }^{2}$, YONGHUA FEI ${ }^{1}$, YANHUA LEI ${ }^{1}$, FENGXIANG LU ${ }^{1}$, \\ PING GUO $^{1}$, WEI LI ${ }^{1}$ and XUEHONG XUN ${ }^{1}$ \\ ${ }^{1}$ Department of Otolaryngology, Head and Neck Surgery, The First People's Hospital of Jining, Jining, Shandong 272000; \\ ${ }^{2}$ Department of Obstetrics, The First Maternity and Child Health Hospital of Jining, Jining, Shandong 272000, P.R. China
}

Received December 21, 2017; Accepted June 4, 2018

DOI: $10.3892 /$ or.2018.6506

\begin{abstract}
The aim of the present study was to investigate the key genes, miRNAs and pathways in hypopharyngeal squamous cell carcinoma (HPSCC) and to elucidate the mechanisms underlying HPSCC development. The gene and microRNA (miRNA) expression profiles of HPSCC tissues and adjacent normal tissues from three subjects were obtained. Differentially expressed genes (DEGs) and differentially expressed miRNAs were identified in HPSCC. Functional annotation and protein-protein interaction (PPI) network were conducted to elucidate the biological functions of DEGs. A total of 160 DEGs (16 upregulated and 144 downregulated genes)
\end{abstract}

Correspondence to: Dr Ping Guo, Department of Otolaryngology, Head and Neck Surgery, The First People's Hospital of Jining, 6 Jiankang Road, Rencheng, Jining, Shandong 272000, P.R. China E-mail: guo_ping720608@163.com

Abbreviations: ADAM10, ADAM metallopeptidase; CGB3, chorionic gonadotropin beta subunit 3; CSDE1, cold shock domain containing E1; DEGs, differentially expressed genes; FDR, false discovery rate; FPKM, fragments per kilobase of exon per million fragments mapped; GRK6, G protein-coupled receptor kinase 6; GAPLINC, gastric adenocarcinoma associated, positive CD44 regulator, long intergenic non-coding RNA; GO, Gene Ontology; GRP78, glucose-regulated protein 78; HYMAI, hydatidiform mole associated and imprinted; HPSCC, hypopharyngeal squamous cell carcinoma; MALAT1, metastasis associated lung adenocarcinoma transcript 1; NONO, non-POU domain containing octamer binding; NSCLC, non-small cell lung cancers; PPI, protein-protein interaction; RPL26, ribosomal protein L26; RPS6, ribosomal protein S6; RIN, RNA integrity number; SNAI2, snail family transcriptional repressor 2; SKP1, S-phase kinase associated protein 1; TCGA, The Cancer Genome Atlas; TNFR1, tumor necrosis factor receptor 1 ; ZACN, zinc activated ion channel; ZNF385C, zinc finger protein 385C

Key words: hypopharyngeal squamous cell carcinoma, RNA-sequencing, differentially expressed genes, protein-protein interaction network, expression profiling and 79 differentially expressed miRNAs (48 upregulated and 31 downregulated miRNAs) were identified in HPSCC. The deregulated genes were significantly involved in spliceosome, cell cycle and RNA degradation. In the PPI network, S-phase kinase associated protein 1 (SKP1), non-POU domain containing octamer binding (NONO) and zinc activated ion channel (ZACN) were identified as hub proteins. On the whole, the present study may help to gain a comprehensive understanding of tumorigenesis in HPSCC and provide valuable information for early diagnosis and drug design of HPSCC in future research.

\section{Introduction}

Hypopharyngeal squamous cell carcinoma (HPSCC) is a common type of head and neck cancer that is associated with a high invasiveness and a poor prognosis. Recently, surgical resection along with chemoradiation therapy have been indicated as a good modality for HPSCC treatment; however, the majority of patients with HPSCC have an unfavorable prognosis due to diagnosis at an advanced stage with the presence of distant metastasis and therefore, the opportunity for radical treatment is lost. It has been reported that the overall survival rate of patients with HPSCC is only $15-45 \%(1,2)$. The etiological factors of HPSCC are unclear. A series of recent studies have described that smoking (active and passive), alcohol consumption and exposure to the human papilloma virus may be risk factors for the development of HPSCC (3-5).

The pathophysiological mechanisms of HPSCC are not yet well understood. Previous studies have demonstrated that ectopically expressed genes, microRNAs (miRNAs or miRs) and long non-coding RNAs were involved in the initiation, development and prognosis of HPSCC. Tumor necrosis factor receptor 1 (TNFR1) is a membranous receptor that anchors on the surface of the cell membrane, which belongs to the TNF receptor superfamily $(6,7)$. The upregulation of TNFR1 has been shown to be associated with clinical staging, T stage, cervical lymph node metastasis and histological grade in HPSCC (8). The immunoglobulin heavy chain binding protein (BiP)/glucose-regulated protein 78 (GRP78) plays an important role in the endoplasmic reticulum stress and is 
known to be highly expressed in various human neoplasms. A decreased expression of GRP78/BiP has been reported to predict a poor overall survival and progression-free survival of patients with advanced HPSCC (9). The downregulation of miR-140-5p has also been shown to be associated with tumor stage and lymph node metastasis, and the restoration of miR-140-5p inhibits cell migration and invasion in HPSCC by targeting ADAM metallopeptidase (ADAM10), which is involved in the Notch1 signaling pathway (10). The expression of AB209630, a long non-coding RNA, has been shown to be markedly lower in HPSCC cell lines and tumor tissues compared with the normal cells and tissues, and functions as a tumor suppressor in HPSCC. A high expression of AB209630 significantly has been shown to inhibit the growth, metastasis and invasion of HSPCC in vitro, and a decreased expression of AB209630 predicts a poorer prognosis (11). In addition, abnormal methylation is associated with tumorigenesis in HSPCC. The hypermethylation of $\mathrm{G}$ protein-coupled receptor kinase 6 (GRK6) has been observed in HPSCC tissues compared to the matched adjacent normal tissues. GRK6 is also associated with tumor invasion and TNM stage in HPSCC (12).

HPSCC is a common malignancy with a poor prognosis. To the best of our knowledge, the expression profiling of mRNAs and miRNAs via RNA-sequencing has not yet been documented in HPSCC. In the present study, we used high-throughput RNA-sequencing to examine gene and miRNA expression and to investigate the functional significance of aberrantly expressed genes and miRNAs in HSPCC, with the aim of providing the groundwork for the elucidation of HPSCC tumorigenesis and potential biomarkers for the early diagnosis of HPSCC.

\section{Materials and methods}

Patients and samples. A total of 3 patients diagnosed with HPSCC were enrolled in this study from the First People's Hospital of Jining from August, 2015 to January, 2016. The mean age of the 3 patients with HPSCC was 60.7 years (range, 56-64 years). All 3 patients with HPSCC patients with squamous cell carcinoma were male. All patients had lymph node metastasis tumor loci. Primary HPSCC tissues and adjacent normal tissues of patients were obtained through surgical resection. The TNM stage and tumor grade of the patients are presented in Table I. The study was approved by the Ethics Committee of the First People's Hospital of Jining, and informed written consent was obtained from all patients. Primary tumors and adjacent normal tissues of patients with HPSCC were obtained based on the Declaration of Helsinki.

Isolation of RNA. A total of 6 specimens from the 3 patients were used for RNA isolation using TRIzol reagent (Invitrogen; Thermo Fisher Scientific, Inc., Waltham, MA, USA) according to the manufacturer's instructions. RNA quality and quantity were assessed using the NanoDrop 2000 spectrophotometer (NanoDrop Technologies; Thermo Fisher Scientific) and Agilent 2100 bioanalyzer (Agilent Technologies $\mathrm{GmbH}$, Waldron, Germany). The average RNA quantity for the specimens was $73.42 \mu \mathrm{g}(0.84-174.98 \mu \mathrm{g})$ with RNA integrity number (RIN) values between 1.0 and 7.6.
Library preparation and RNA sequencing. The Illumina TruSeq RNA Sample Prep kit (Illumina, Inc., San Diego, CA, USA) was used for the library preparation according to the manual. PolyT oligo-conjugated magnetic beads were used to enrich the RNA with polyA+ tail, followed by mRNA fragmentation, first strand cDNA synthesis, second strand cDNA synthesis and end repair. Subsequenlty, the product was ligated to Illumina TruSeq adaptors. Following PCR amplification, enriched cDNA libraries were sequenced using the Illumina HiSeq 2500 sequencing platform (Illumina).

Data preprocessing. The raw data from high-throughput RNA-sequencing was translated into raw FASTQ sequence data by base calling. Raw RNA-sequencing data were filtered and trimmed using FASTx-Tool SeqPrep (https://github.com/jstjohn/SeqPrep) and Sickle (https://github. com/najoshi/sickle). Clean and trimmed FASTQ reads were aligned to the human hg19 genome by using TopHat (version 1.3.1; Center for Computational Biology, Johns Hopkins University, Baltimore, MD, USA) (13). The aligned read files were then processed using Cufflinks version 1.2.1 software package (Trapnell Lab, Seattle, WA, USA) which assessed the abundance of genes (14). Fragments per kilobase of transcript per million mapped reads (FPKM) was used to determine the transcription abundance of each gene.

Differentially expressed genes (DEGs) and miRNAs. The DEGs between HPSCC tumor and adjacent normal tissues were carried out using paired t-tests and limma package in $\mathrm{R}$ (15). The false discovery rate (FDR) was performed; multiple testing corrections of raw P-values were performed using the Benjamini and Hochberg method $(16,17)$. The genes with an FDR $<0.05$ and abs ( $\log _{2}$ fold change) $>1$ were screened as DEGs. A two-way hierarchical clustering analysis was conducted to assess the similarity of gene expression patterns between samples, and the results were displayed in a heatmap using the 'pheatmap' package (18). In addition, DEGseq (http://bioconductor.org/packages/DEGseq/) was applied to quantify the expression of miRNAs. miRNAs with P-value $<0.001$ and abs $\left(\log _{2} \mathrm{FC}\right)>2$ were screened as differentially expressed miRNAs.

Analysis of the miRNA target genes. Identifying the target genes of miRNAs is a key step towards studying the function of miRNAs in specific tissues and cells. In the present study, 6 miRNA-target prediction tools (DIANAmT, miRanda, miRDB, miRWalk, PICTAR5 and TargetScan) were applied to predict the target genes of differentially expressed miRNAs. The miRNA-targets that were predicted by $>4$ algorithms or verified by experiment in the miRWalk database were identified. All miRNA-target pairs were obtained, which were not only predicted by algorithms (or verified by experiment), but also negatively associated in the expression level. The miRNA-target regulatory network was then constructed, which was visualized using Cytoscape (19).

Functional annotation of DEGs. The Gene Ontology (GO) function was used to elucidate the biological function of DEGs in biological process, molecular function and cellular component using the GeneCodis 3 online software 
Table I. Basic characteristics of patients with HPSCC.

\begin{tabular}{|c|c|c|c|c|c|c|c|c|c|}
\hline $\begin{array}{l}\text { Patient } \\
\text { ID }\end{array}$ & $\begin{array}{c}\text { Age } \\
\text { (years) }\end{array}$ & Sex & $\begin{array}{l}\text { Cigarettes } \\
\text { per day }\end{array}$ & $\begin{array}{l}\text { Years of } \\
\text { smoking }\end{array}$ & $\begin{array}{l}\text { Alcohol consumption } \\
\text { each day }(\mathrm{g})\end{array}$ & $\begin{array}{l}\text { Years of alcohol } \\
\text { consumption }\end{array}$ & $\begin{array}{l}\text { TNM } \\
\text { stage }\end{array}$ & $\begin{array}{l}\text { Histological } \\
\text { feature }\end{array}$ & $\begin{array}{l}\text { Tumor } \\
\text { grade }\end{array}$ \\
\hline 1 & 62 & Male & 20 & 40 & 100 & 30 & T2N1M0 & $\mathrm{SCC}$ & Medium \\
\hline 2 & 56 & Male & 20 & 30 & 250 & 30 & T2N1M0 & $\mathrm{SCC}$ & Medium \\
\hline 3 & 64 & Male & 20 & 30 & No details & No details & T3N1M0 & $\mathrm{SCC}$ & Medium \\
\hline
\end{tabular}

HPSCC, hypopharyngeal squamous cell carcinoma.

Table II. RNA quantity and quality measurements of 6 samples.

\begin{tabular}{|c|c|c|c|c|}
\hline Sample ID & RNA volume $(\mu 1)$ & RNA concentration $(\mathrm{ng} / \mu \mathrm{l})$ & RNA amount $(\mu \mathrm{g})$ & RIN \\
\hline $1 \mathrm{C}$ & 38 & 2,723 & 103.47 & 4 \\
\hline $2 \mathrm{C}$ & 65 & 2,692 & 174.98 & 7.6 \\
\hline $3 \mathrm{C}$ & 27 & 3,288 & 88.78 & 7.5 \\
\hline $1 \mathrm{~N}$ & 14 & 334 & 4.68 & 5.7 \\
\hline $2 \mathrm{~N}$ & 12 & 70 & 0.84 & N/A \\
\hline $3 \mathrm{~N}$ & 38 & 1,784 & 67.79 & 4.7 \\
\hline
\end{tabular}

C, primary tissues of hypopharyngeal squamous cell carcinoma; N, adjacent normal tissues; RIN, RNA integrity number; N/A, not available.

Table III. RNA-sequencing of the specimens.

\begin{tabular}{|c|c|c|c|c|c|}
\hline Sample_ID & Total reads & Total bases & Q20\% & Q30\% & Average coverage \\
\hline $1 \mathrm{C}$ & $4.4 \times 10^{7}$ & $5.6 \times 10^{9}$ & 96.66 & 93.47 & 99.1863479139598 \\
\hline $2 \mathrm{C}$ & $3.5 \times 10^{7}$ & $4.3 \times 10^{9}$ & 96.61 & 93.33 & 99.4073847620807 \\
\hline $3 \mathrm{C}$ & $3.4 \times 10^{7}$ & $4.2 \times 10^{9}$ & 96.68 & 93.41 & 99.2552832336352 \\
\hline $1 \mathrm{~N}$ & $4.3 \times 10^{7}$ & $5.4 \times 10^{9}$ & 96.27 & 92.79 & 99.348671268904 \\
\hline $3 \mathrm{~N}$ & $3.5 \times 10^{7}$ & $4.4 \times 10^{9}$ & 96.58 & 93.32 & 99.2810150213976 \\
\hline
\end{tabular}

C, primary tissues of hypopharyngeal squamous cell carcinoma; N, adjacent normal tissues; Q20, the percentage of bases with quality value $>20$; Q30, the percentage of bases with quality value $>30$.

(http://genecodis.cnb.csic.es/analysis) (20). $\mathrm{P}<0.01$ was set as the cut-off for selecting significantly enriched functional GO terms. KOBAS version 2.0 software (http://kobas.cbi.pku.edu. cn) was used to enrich the signaling pathways of DEGs (21). $\mathrm{P}<0.05$ was set as the threshold for determining significantly enriched pathways.

Protein-protein interaction network(PPI). In order to elucidate the protein interactions between upregulated and downregulated DEGs in HPSCC, the BioGRID database was used to screen pairs of interacting proteins (22). The PPI network was visualized using Cytoscape (http://cytoscape.org/) (23). In the network, nodes represent proteins and edges represent interaction between two proteins.

Validation of the expression of selected DEGs in The Cancer Genome Atlas (TCGA). TCGA dataset was used to validate the expression of selected DEGs in HPSCC patients with a large sample size by using the online software SurvExpress (http://bioinformatica.mty. itesm. mx:8080/Biomatec/SurvivaX.jsp).

\section{Results}

RNA sequencing of HPSCC specimens. Total RNA was extracted from HPSCC tissues and adjacent normal controls from 3 patients. A total of 5 out of 6 samples, including $1 \mathrm{C}, 1 \mathrm{~N}, 3 \mathrm{C}, 3 \mathrm{~N}$ and $2 \mathrm{C}$ passed the assessment for RNA quality and quantity. Sample $2 \mathrm{~N}$ did not pass the assessment, as the RIN value was not applicable (Table II). A total of 5 samples were used for library construction and RNA-sequencing. For each sample, RNA-sequencing reads were generated and yielded 34-44 million sequencing reads per sample (Table III). All sequencing reads were aligned 
Table IV. DEGs in HPSCC.

\begin{tabular}{|c|c|c|c|c|}
\hline Gene ID & Gene symbol & Log2FC & P-value & FDR \\
\hline \multicolumn{5}{|c|}{ Upregulated genes } \\
\hline 353174 & $Z A C N$ & 6.288149 & $8.86 \mathrm{E}-05$ & 0.038292 \\
\hline 1082 & $C G B 3$ & 5.765826 & $4.12 \mathrm{E}-05$ & 0.034011 \\
\hline 201181 & ZNF385C & 5.310858 & 0.000127 & 0.039757 \\
\hline 126567 & $C 2 C D 4 C$ & 5.256596 & 0.000222 & 0.049962 \\
\hline 84696 & $A B H D 1$ & 5.10952 & 4.07E-05 & 0.034011 \\
\hline 6370 & CCL25 & 5.035685 & $5.76 \mathrm{E}-05$ & 0.035804 \\
\hline 693222 & MIR637 & 4.830281 & $6.51 \mathrm{E}-05$ & 0.035863 \\
\hline 692091 & SNORD23 & 4.628719 & $3.74 \mathrm{E}-05$ & 0.033502 \\
\hline 9075 & CLDN2 & 4.580931 & 0.000195 & 0.047531 \\
\hline 6082 & SNORD20 & 4.49704 & $8.54 \mathrm{E}-05$ & 0.038072 \\
\hline 284339 & TMEM145 & 4.395233 & $8.36 \mathrm{E}-05$ & 0.038072 \\
\hline 2251 & $F G F 6$ & 3.962287 & $6.55 \mathrm{E}-05$ & 0.035863 \\
\hline 136371 & $A S B 10$ & 3.961177 & 0.000138 & 0.040535 \\
\hline 248 & $A L P I$ & 3.959662 & 7.79E-05 & 0.038041 \\
\hline 54964 & C1orf56 & 3.849454 & 0.000166 & 0.044327 \\
\hline 84939 & $M U M 1$ & 3.145926 & $9.19 \mathrm{E}-05$ & 0.038292 \\
\hline \multicolumn{5}{|c|}{ Downregulated genes } \\
\hline 6154 & RPL26 & -10.6837 & $1.06 \mathrm{E}-06$ & 0.014705 \\
\hline 6194 & RPS6 & -9.89489 & $1.14 \mathrm{E}-06$ & 0.014705 \\
\hline 6500 & $S K P 1$ & -7.78013 & $3.26 \mathrm{E}-06$ & 0.030707 \\
\hline 8531 & $Y B X 3$ & -7.37473 & $2.26 \mathrm{E}-05$ & 0.033502 \\
\hline 347 & $A P O D$ & -7.36529 & $6.56 \mathrm{E}-06$ & 0.033502 \\
\hline 51614 & ERGIC3 & -7.28305 & 0.000122 & 0.03936 \\
\hline 4501 & $M T 1 X$ & -6.78769 & 0.000215 & 0.049189 \\
\hline 3486 & $I G F B P 3$ & -6.56019 & $6.70 \mathrm{E}-06$ & 0.033502 \\
\hline 7812 & $C S D E 1$ & -6.49789 & $5.73 \mathrm{E}-06$ & 0.033502 \\
\hline 4841 & NONO & -6.45686 & $8.40 \mathrm{E}-06$ & 0.033502 \\
\hline 6317 & SERPINB3 & -6.45555 & 0.000213 & 0.049086 \\
\hline 5360 & PLTP & -6.29414 & $2.00 \mathrm{E}-05$ & 0.033502 \\
\hline 1528 & $C Y B 5 A$ & -6.28125 & $2.21 \mathrm{E}-05$ & 0.033502 \\
\hline 51596 & CUTA & -6.24975 & 0.000199 & 0.048247 \\
\hline 57035 & $R S R P 1$ & -6.20271 & 0.000205 & 0.048326 \\
\hline 7385 & $U Q C R C 2$ & -6.01731 & 8.71E-06 & 0.033502 \\
\hline 1639 & DCTN1 & -5.79807 & 0.000143 & 0.040725 \\
\hline 1212 & $C L T B$ & -5.70891 & 0.000204 & 0.048326 \\
\hline 5589 & PRKCSH & -5.58244 & $8.30 \mathrm{E}-05$ & 0.038072 \\
\hline 6194 & RPS6 & -9.89489 & $1.14 \mathrm{E}-06$ & 0.014705 \\
\hline 340277 & FAM221A & -3.26588 & 1.30635 & -17.5303 \\
\hline
\end{tabular}

DEGs, differentially expressed genes; HPSCC, hypopharyngeal squamous cell carcinoma; FDR, false discovery rate.

to the human hg19 genome by using TopHat and FPKM and the relative expression of genes was determined using the Cufflinks tool.

DEGs and differentially expressed miRNAs between primary HPSCC and adjacent normal controls. A total of 160 DEGs, including 16 upregulated and 144 downregulated genes, were identified in the HPSCC tumors compared to the adjacent normal controls using the screening criteria $\mathrm{FDR}<0.05$ and abs $\left(\log _{2} \mathrm{FC}\right)>1$ (data not shown). In addition, a total of 79 differentially expressed miRNAs (48 upregulated and 31 downregulated miRNAs) were identified in the HPSCC tumors compared to adjacent normal controls using the screening criteria $\mathrm{P}<0.001$ and abs $\left(\log _{2} \mathrm{FC}\right)>2$ (data not shown).

As shown in Table IV, zinc activated ion channel $(Z A C N)$, chorionic gonadotropin $\beta$ subunit 3 (CGB3) and zinc finger protein $385 \mathrm{C}$ (ZNF385C) were the top 3 upregulated genes. 


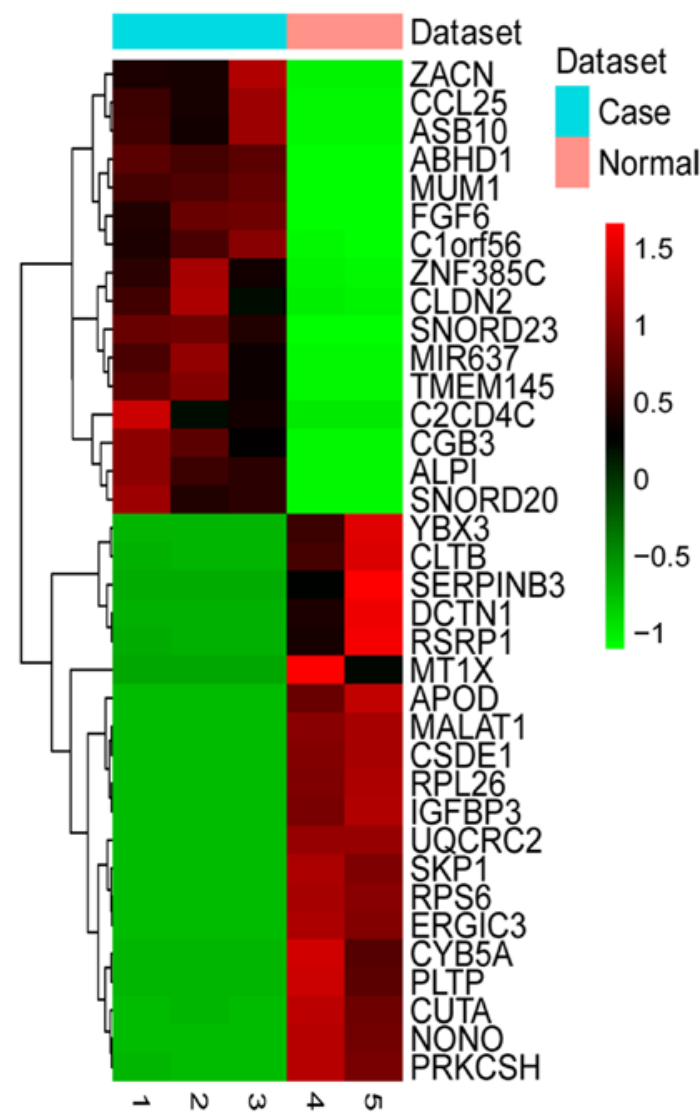

Figure 1. Hierarchical clustering analysis based on the expression profile of the top 20 DEGs in HPSCC compared to adjacent normal tissues. Turquoise and pink indicate the HPSCC and adjacent normal tissues, respectively Red represents the relative expression level of genes that was higher than the mean expression level, and green represents the relative expression of genes that was lower than the mean expression level. DEGs, differentially expressed genes; HPSCC, hypopharyngeal squamous cell carcinoma.

Ribosomal protein L26 (RPL26), ribosomal protein S6 (RPS6) and S-phase kinase associated protein $1(S K P I)$ were the top 3 downregulated genes in HPSCC. The expression pattern of the top 20 upregulated and downregulated DEGs was examined by two-way hierarchical clustering analysis (Fig. 1). Compared to the normal control, metastasis-associated lung adenocarcinoma transcript 1 (MALAT1) was a significantly downregulated long non-coding RNA in HPSCC based on our RNA-sequencing data (FDR=0.014705). The top 20 differentially expressed miRNAs are shown in Table V. As shown in Table V, hsa-let-7i-5p, hsa-miR-136-5p and hsa-miR-143-5p were the top 3 upregulated miRNAs in HPSCC, and hsa-miR-15a-5p, hsa-miR-2278 and hsa-miR-125a-5p were the top 3 downregulated miRNAs in HPSCC.

miRNA target gene interactions. Following target correlation analysis, a total of 339 miRNA-target pairs were obtained in HPSCC. A total of 228 upregulated miRNA-target pairs and 9 downregulated miRNA-target pairs were predicted using 6 prediction tools. A total of 101 upregulated miRNAs-target pairs and 1 downregulated miRNAs-target pair were validated in the miRWalk dataset. The top 10 miRNAs that targeted the majority of genes are listed in Table VI. The miRNA-target network between DEGs and differentially expressed miRNAs is presented in Fig. 2.
Table V. Top 20 differentially expressed miRNAs in HPSCC.

\begin{tabular}{lcc}
\hline miRNA symbol & Log2FC & P-value \\
\hline $\begin{array}{l}\text { Upregulated miRNAs } \\
\text { hsa-let-7i-5p }\end{array}$ & 2.122547495 & 0 \\
hsa-miR-136-5p & 2.444466751 & 0 \\
hsa-miR-143-5p & 2.976688335 & 0 \\
hsa-miR-370-3p & 3.344940583 & 0 \\
hsa-miR-140-3p & 3.395556571 & 0 \\
hsa-let-7g-5p & 9.933859336 & $8.71 \mathrm{E}-85$ \\
hsa-miR-106b-3p & 9.933859336 & $8.71 \mathrm{E}-85$ \\
hsa-miR-127-3p & 9.933859336 & $8.71 \mathrm{E}-85$ \\
hsa-miR-148b-3p & 9.933859336 & $8.71 \mathrm{E}-85$ \\
hsa-miR-187-3p & 9.933859336 & $8.71 \mathrm{E}-85$ \\
Downregulated miRNAs & & \\
hsa-miR-15a-5p & -12.79407766 & 0 \\
hsa-miR-2278 & -12.05711064 & $1.56 \mathrm{E}-243$ \\
hsa-miR-125a-5p & -10.472141 & $3.27 \mathrm{E}-107$ \\
hsa-miR-1269a & -10.472141 & $3.27 \mathrm{E}-107$ \\
hsa-miR-135b-5p & -10.472141 & $3.27 \mathrm{E}-107$ \\
hsa-miR-18a-3p & -10.472141 & $3.27 \mathrm{E}-107$ \\
hsa-miR-19b-3p & -10.472141 & $3.27 \mathrm{E}-107$ \\
hsa-miR-200b-3p & -10.472141 & $3.27 \mathrm{E}-107$ \\
hsa-miR-203b-3p & -10.472141 & $3.27 \mathrm{E}-107$ \\
hsa-miR-20a-5p & -10.472141 & $3.27 \mathrm{E}-107$ \\
\hline
\end{tabular}

HPSCC, hypopharyngeal squamous cell carcinoma.

Functional annotation of DEGs. GO annotation of the 160 identified DEGs in HPSCC was performed to elucidate the biological roles of DEGs using the GeneCodis 3 online software. $\mathrm{P}<0.05$ was used to determine significantly enriched GO terms. The most enriched 'molecular functions' of the DEGs were carbon-sulfur lyase activity (GO, 0016846), phosphotransferase activity, for other substituted phosphate groups (GO, 0016780) and CDP-alcohol phosphatidyltransferase activity (GO, 0017169). The most enriched 'cellular components' were intracellular organelle part (GO, 0044446), organelle part (GO, 0044422) and cytoplasm (GO, 0005737). The most enriched 'biological processes' were mRNA metabolic process (GO, 0016071), RNA processing (GO, 0006396) and RNA splicing (GO, 0008380) (Figs. 3-5).

KEGG pathway enrichment. We performed KEGG pathway enrichment analysis for DEGs using KOBAS version 2.0. $\mathrm{P}<0.05$ was used as the criteria for pathway enrichment. The most enriched pathways were spliceosome (hsa03040), cell cycle (hsa04110) and RNA degradation (hsa03018) (Fig. 6).

PPI network of DEGs in primary HPSCC compared to adjacent normal controls. PPI networks of the top 20 upregulated and downregulated DEGs in HPSCC compared to adjacent normal controls were determined using Cytoscape, which consisted of 673 nodes and 812 edges (data not shown). The proteins that had high connectivity with other proteins were 
Table VI. Top 10 miRNAs that targeted the majority of genes.

\begin{tabular}{|c|c|c|c|}
\hline miRNA & Up/downregulated & $\begin{array}{l}\text { Count of } \\
\text { targets }\end{array}$ & Target genes \\
\hline hsa-miR-193b-3p & Upregulated & 18 & $\begin{array}{l}\text { CDK9, HNRNPUL1, ELK3, ACOT9, GLO1, HPRT1, IRF1, MCM3, } \\
\text { NONO, SCLY, RPL26, YBX3, CTSC, ERC1, MDM2, CSDE1,CGNL1, } \\
\text { BCAR1 }\end{array}$ \\
\hline hsa-miR-214-3p & Upregulated & 17 & $\begin{array}{l}\text { ERC1, CDK9, SYNPO, NUDT16, DCTN1, CLASP1, ZDHHC8, APOD, } \\
\text { INCENP, MYO1E, BIK, TRA2B, TFAM, ITCH, CGNL1, MPZL1, } \\
\text { JAG1 }\end{array}$ \\
\hline hsa-miR-497-5p & Upregulated & 14 & $\begin{array}{l}\text { RBBP6, YWHAH, CDS1, CTSC, SYNPO, NUDT16, INCENP, IRF1, } \\
\text { CSDE1, PPP1R14C, CGNL1, MPZL1, MTSS1, CDC42SE2 }\end{array}$ \\
\hline hsa-miR-29b-2-5p & Upregulated & 13 & $\begin{array}{l}\text { TMEM18, NUDT16, CPM, CPT1A, ERC1, C2CD3, NFYB, NONO, } \\
\text { CXorf40B, LEPROT, TFAM, CGNL1, CTSC }\end{array}$ \\
\hline hsa-miR-125b-5p & Upregulated & 12 & $\begin{array}{l}\text { EXOC7, LSM4, PIGF, SYNPO, DCTN1, ZDHHC8, IGFBP3, IRF1, } \\
\text { NADK, CSDE1, ITCH, MPZL1 }\end{array}$ \\
\hline hsa-miR-3150b-3p & Upregulated & 12 & $\begin{array}{l}\text { KAT7, NUDT16, CPM, ERC1, HCCS, NFYB, CRLS1, LEPROT, } \\
\text { PRPSAP2, CDC42SE2, SOD3, TULP3 }\end{array}$ \\
\hline hsa-miR-185-5p & Upregulated & 11 & $\begin{array}{l}\text { KAT7, INCENP, MDM2, NUDT16, CPM, CPT1A, ERC1, HCCS, } \\
\text { LEPROT, PPP1R14C, MPZL1 }\end{array}$ \\
\hline hsa-miR-342-3p & Upregulated & 11 & $\begin{array}{l}\text { DARS, ERC1, ACOT9, LETMD1, PRKCSH RPL26, NUDT16, } \\
\text { ZDHHC8, CGNL1, MPZL1 }\end{array}$ \\
\hline hsa-miR-378a-5p & Upregulated & 11 & $\begin{array}{l}\text { IRF1, RPS6, CTSC, CPM, CPT1A, ERC1, ANKLE2, FTSJ2, NFYB, } \\
\text { TULP3, ITCH }\end{array}$ \\
\hline hsa-miR-629-3p & Upregulated & 11 & $\begin{array}{l}\text { HNRNPUL1, ACOT9, TRIB1, CDK9, CTSC, NUDT16, CPM, CPT1A, } \\
\text { ERC1, SRP54, TFAM }\end{array}$ \\
\hline
\end{tabular}

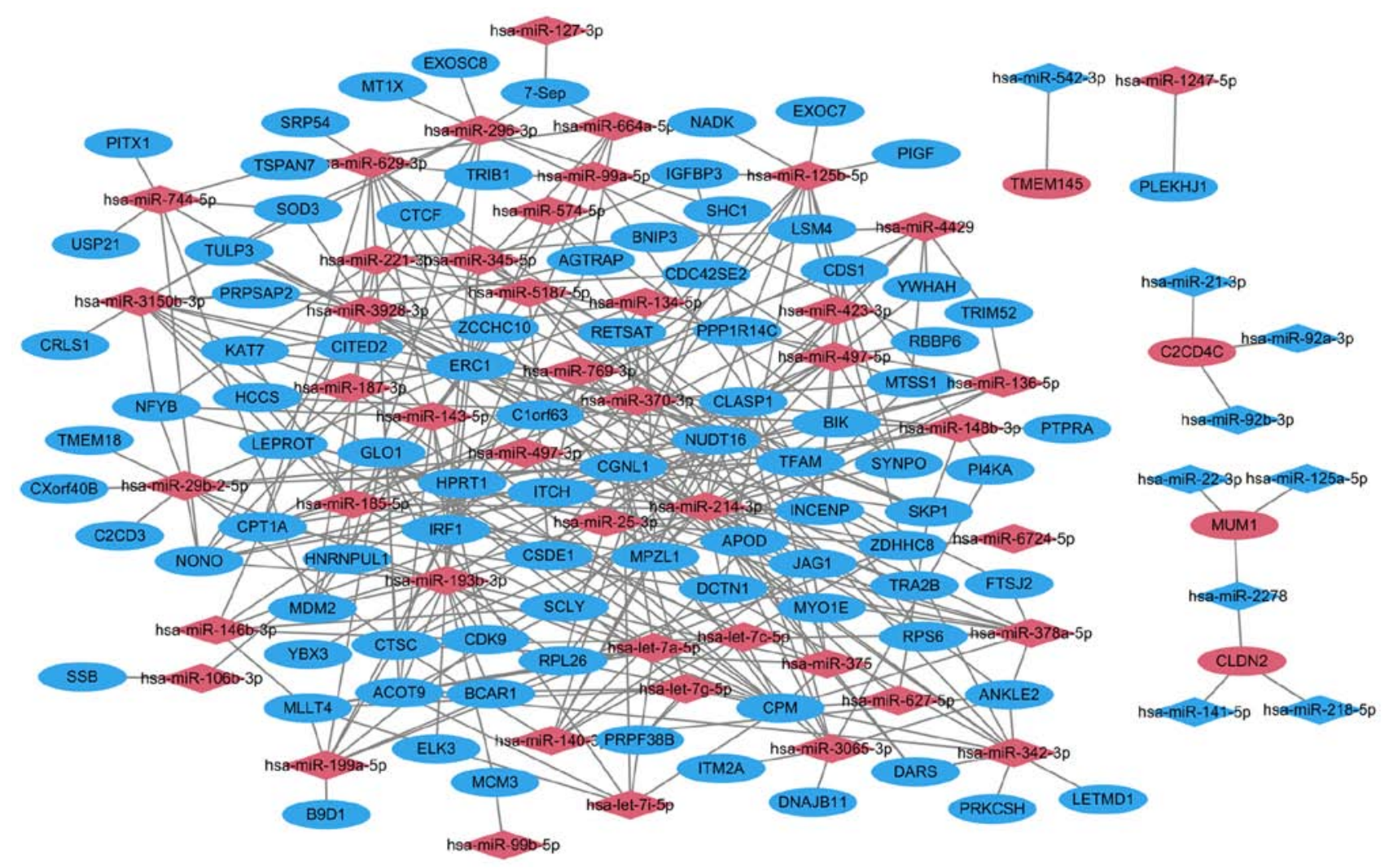

Figure 2. miRNA target network between DEGs and differentially expressed miRNAs in HPSCC. Diamond and ellipse shapes represent the miRNAs and target genes, respectively. Red and blue represent upregulation and downregulation, respectively. DEGs, differentially expressed genes; HPSCC, hypopharyngeal squamous cell carcinoma; miRNA, microRNA. 
GO molecular function

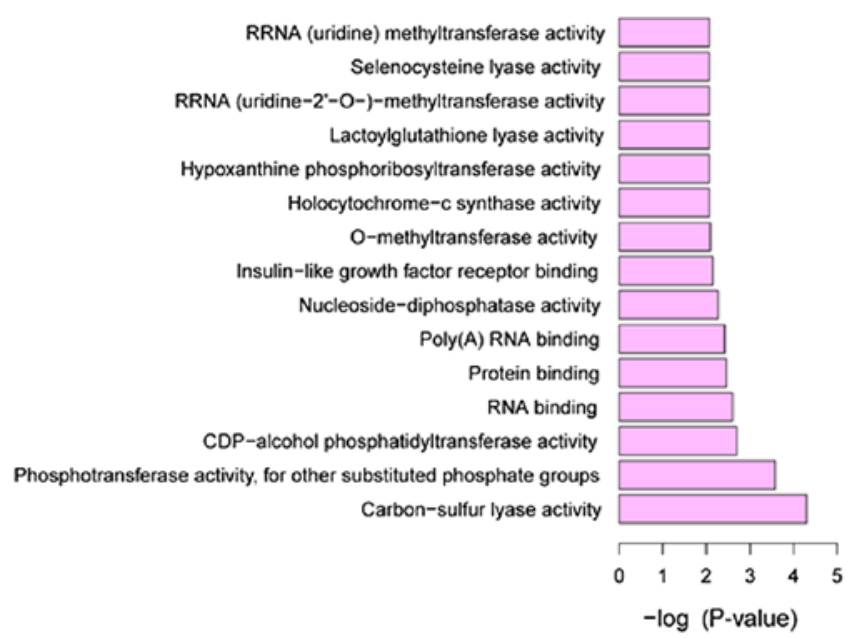

Figure 3. Top 15 significantly enriched molecular functions of DEGs in HPSCC. DEGs, differentially expressed genes; HPSCC, hypopharyngeal squamous cell carcinoma.

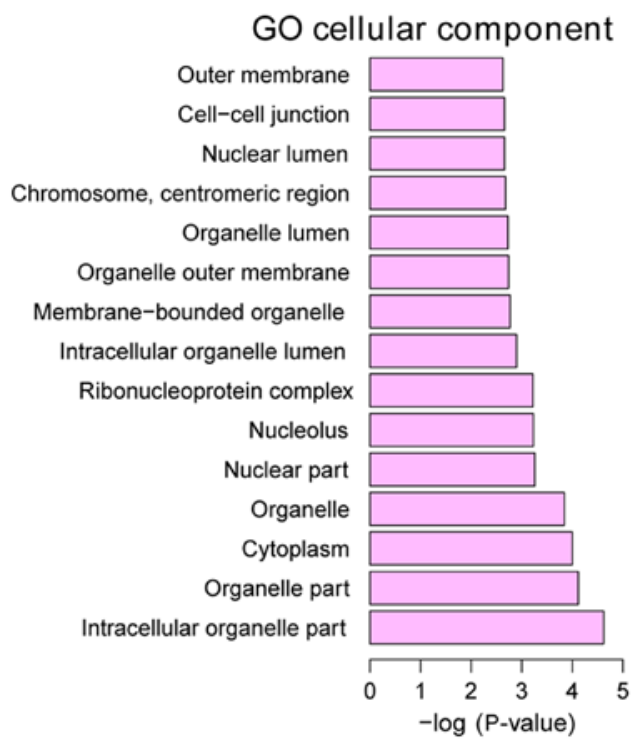

Figure 4. Top 15 significantly enriched cellular components of DEGs in HPSCC. DEGs, differentially expressed genes; HPSCC, hypopharyngeal squamous cell carcinoma.

hub proteins. In the PPI network, SKP1, NONO and ZACN were the hub proteins, which interacted with 166,101 and 70 proteins, respectively (Fig. 7 ).

Expression validation of selected DEGs in TCGA. A total of 5 DEGs [SKP1, ZACN, NONO, cold shock domain containing E1 (CSDE1), chorionic gonadotropin $\beta$ subunit $3(C G B 3)$ and $M A L A T 1]$ were selected to perform the tumor risk evaluation in HPSCC by using the head and neck squamous cell carcinoma datasets (283 samples) in TCGA. $C G B 3, S K P 1$ and $Z A C N$ were upregulated while MALAT1, $N O N O$ and $C S D E 1$ were downregulated in the HPSCC high-risk group (Fig. 8). Additionally, we also performed validation of SKP1, NONO and MALAT1 using the HPSCC dataset in TCGA. The result showed that the expression of

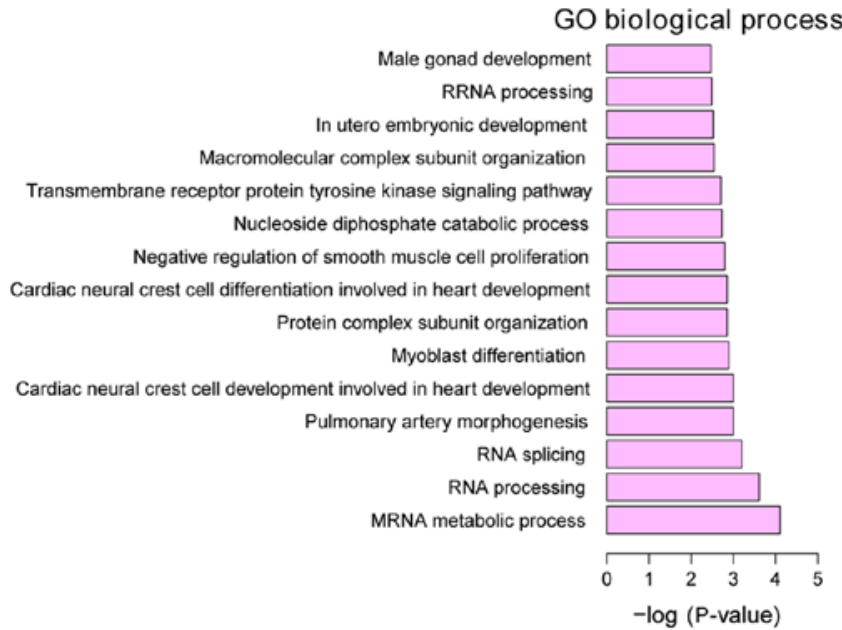

Figure 5. Top 15 significantly enriched biological processes of DEGs in HPSCC. DEGs, differentially expressed genes; HPSCC, hypopharyngeal squamous cell carcinoma.

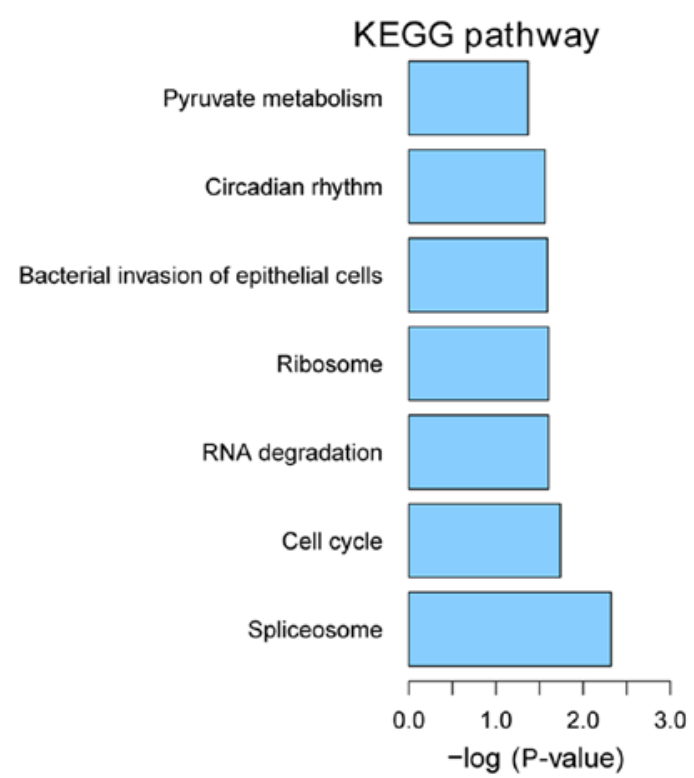

Figure 6. Significantly enriched KEGG pathways of DEGs in HPSCC. DEGs, differentially expressed genes; HPSCC, hypopharyngeal squamous cell carcinoma; KEGG, Kyoto Encyclopedia of Genes and Genomes.

SKP1, NONO and MALATI was decreased in HPSCC tissues compared to the normal control, which was consistent with the RNA-sequencing analysis (Fig. 9).

\section{Discussion}

At present, there is a lack of early detection biomarkers in clinical practice for HPSCC. To the best our knowledge, this is the first study to report the expression pattern of mRNAs and miRNAs in HPSCC via high-throughput RNA sequencing.

SKPI was significantly downregulated in HPSCC compared to adjacent normal controls (Table IV). SKP1 had the highest connectivity with 193 proteins (Fig. 7). According to KEGG signaling pathway enrichment, SKPI was significantly enriched in cell cycle and circadian rhythm. 


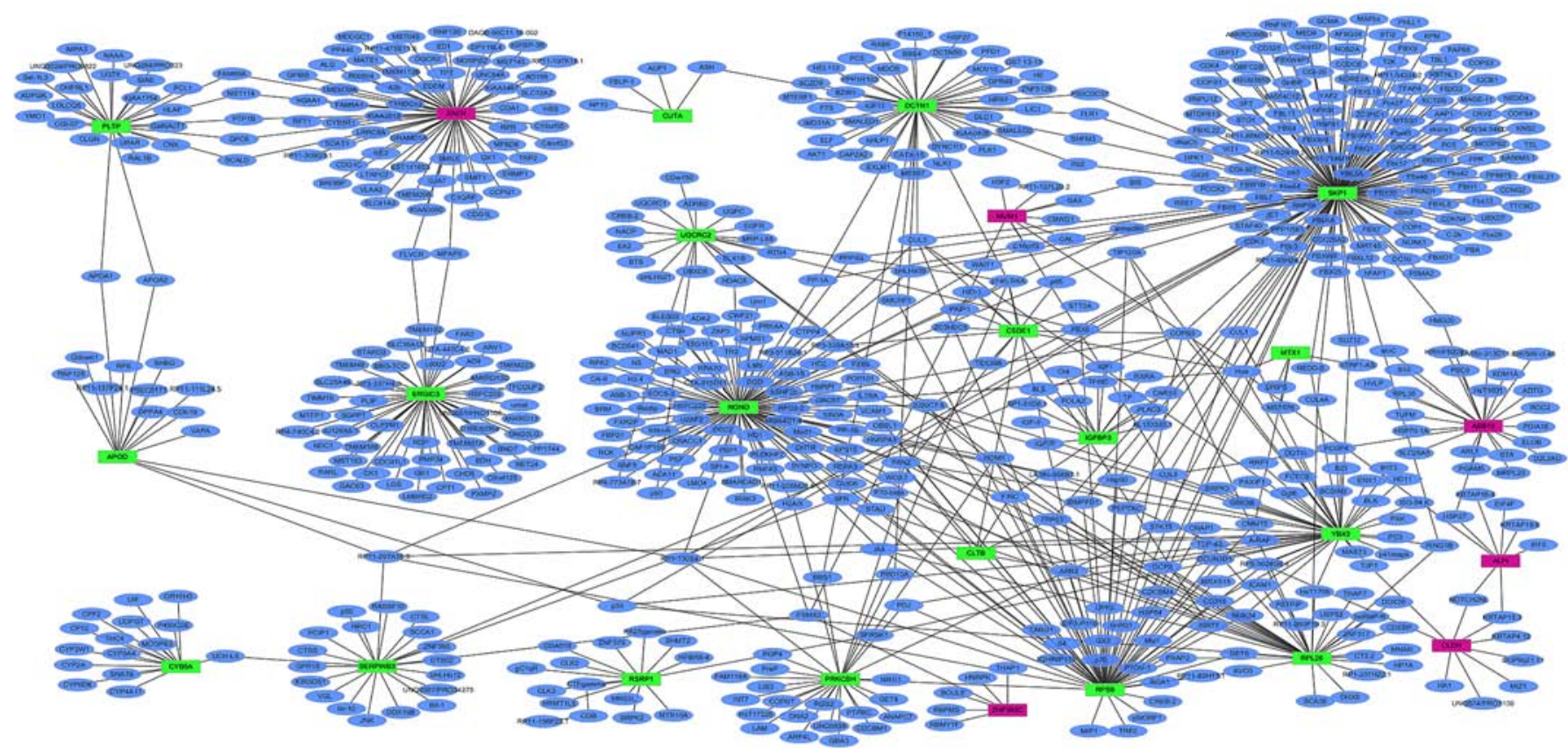

Figure 7. Protein-protein interaction networks of the top 20 upregulated and downregulated DEGs in HPSCC. Red and green rectangle nodes represent upregulated and downregulated DEGs, respectively. Blue circular nodes represent proteins that interact with the proteins encoded by DEG. The solid line indicates the interactions between proteins.

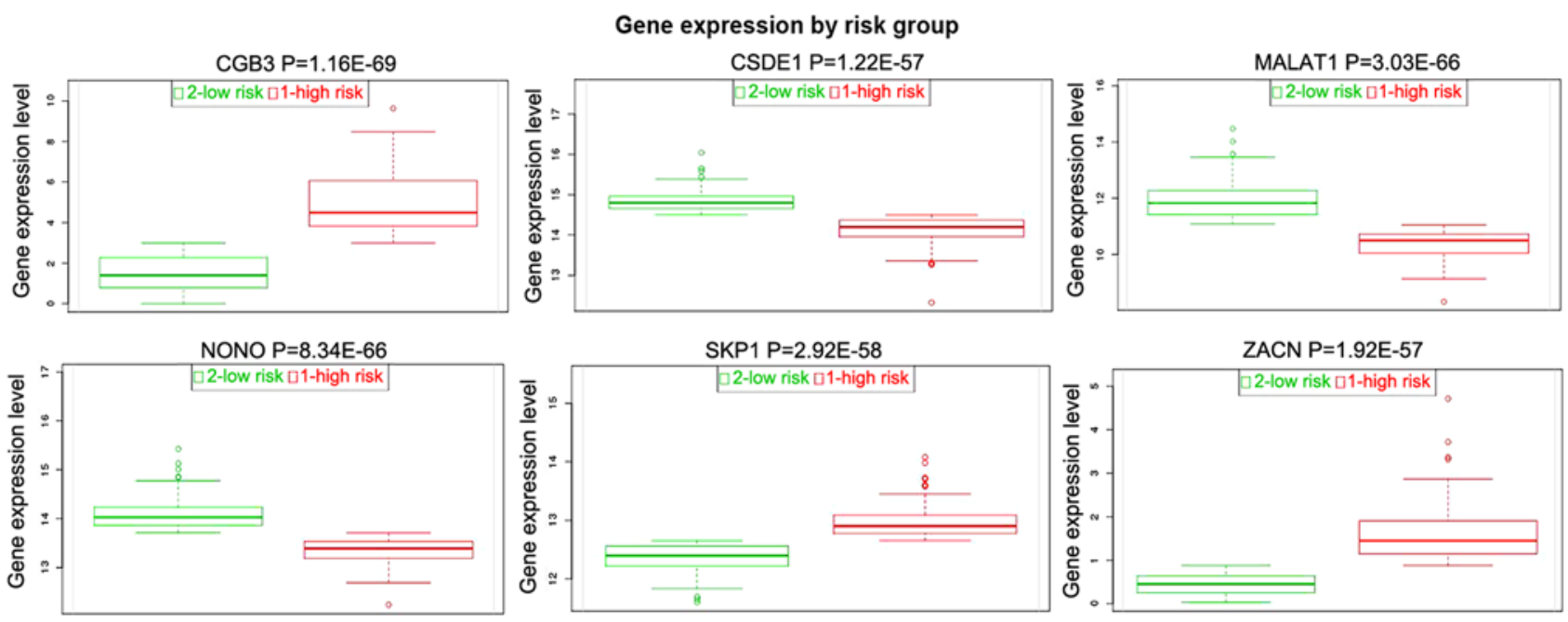

Figure 8. Tumor risk evaluations of SKP1, ZACN, NONO, CSDE1, CGB3 and MALAT1 in the TCGA dataset. CGB3, chorionic gonadotropin beta subunit 3; CSDE1, cold shock domain containing E1; MALAT1, metastasis associated in lung adenocarcinoma transcript 1; NONO, non-POU domain containing octamer binding; SKP1, S-phase kinase associated protein 1; TCGA, The Cancer Genome Atlas; ZACN, zinc activated ion channel.
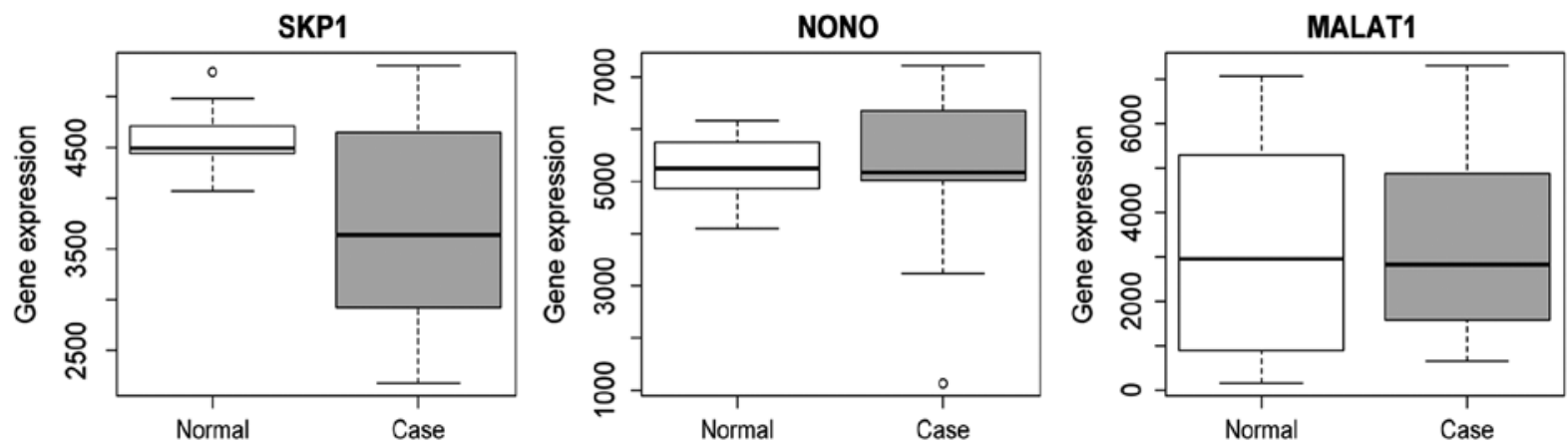

Figure 9. Box plots of SKP1, NONO and MALAT1 in the TCGA dataset. MALAT1, metastasis associated in lung adenocarcinoma transcript 1; NONO, non-POU domain containing octamer binding; SKP1, S-phase kinase associated protein 1; TCGA, The Cancer Genome Atlas. 
In homo sapiens, SKPl encodes S-phase kinase-associated protein 1, which is a scaffold protein of the ubiquitin E3 ligase Skp1/Cullin1/Rbx1/F-box protein complex (SCF complex). The SCF complex catalyzes the ubiquitination of proteins, which are involved in cell-cycle progression, signal transduction and transcription (24). SKPl was overexpressed in $56.3 \%$ of the non-small cell lung cancer (NSCLC) specimens and elevated SKP1 was associated with a poor prognosis (25). The other component of the SCF complex, cullin, is highly expressed in NSCLC tissues and significantly associated with histological differentiation and clinical stage (26). Our finding indicated that SKP1 may play vital roles in the development of HSPCC, which indicates that it may serve as a diagnostic and prognostic biomarker for HSPCC.

Apart from SKP1, ZACN (also termed L2, ZAC) was also a hub protein according to the HSPCC-specific PPI network. ZACN is located at chromosome 17, and it encodes zinc-activated ion channel, which belongs to the cysteine-loop superfamily of ligand-gated ion channels. ZACN mRNA is expressed in various organs and tissues, including the brain, pancreas, liver, lung, heart, kidney and skeletal muscle (27). The overexpression of $Z A C N$ was implicated in transient neonatal diabetes mellitus, which is a rare inherited diabetic syndrome apparent in neonate and again during early adulthood. In a transgenic mouse model, the expression of human $Z A C N$ and hydatidiform mole associated and imprinted (HYMAI) impaired the development of the endocrine pancreas and the function of $\beta$ cells (28). In the present study, ZACN was the most significantly upregulated gene in the HPSCC dataset compared to the adjacent normal control. The overexpression of ZACN in HPSCC was first reported in this study. The biological roles of ZACN overexpression in HPSCC warrant further investigation in in vitro and in vivo studies.

$N O N O$ encodes an RNA-binding protein and functions to regulate transcription and RNA splicing in the nucleus. NONO has been implicated in the progression of various tumor types, including breast and colorectal cancer and melanoma. NONO was also reported to regulate lipid metabolism by binding to SREBP-1A in breast cancer (29).

Gastric adenocarcinoma associated, positive CD44 regulator, long intergenic non-coding RNA (GAPLINC) promotes cell invasion by targeting snail family transcriptional repressor 2 (SNAI2) via binding with $N O N O$ in colorectal cancer (30). As a hub protein of the HSPCC-specific PPI network, NONO was significantly downregulated in HPSCC in this study. In addition, NONO was targeted by hsa-miR-29b-2-5p (Table VI). It has been reported that miR-29b-2-5p was potentially associated with survival in high-grade serous ovarian carcinoma (31). Furthermore, miR-29b-2-5p has been shown to be downregulated in gallbladder cancer (32). It was suggested that NONO may be involved in HPSCC under the regulation of hsa-miR-29b-2-5p.

$C G B 3$ is a member of the glycoprotein hormone $\beta$ chain family and encodes the $\beta 3$ subunit of chorionic gonadotropin (33). Previous studies have indicated that the overexpression of $C G B 3$ plays a role in carcinogenesis $(34,35)$. The synthesis of human chorionic gonadotropin $\beta$ subunit has been detected in $30-50 \%$ of various malignant tumors $(36,37)$. In addition, upregulated $C G B 3$ has been found to be closely associated with the metastatic cancer phenotype, resistance to therapy, as well as with a poor prognosis $(37,38)$. To date, to the best of our knowledge, no study has reported the association between $C G B 3$ and HSPCC. In the present study, an increased $C G B 3$ expression was detected in patients with HSPCC. Hence, it can be concluded that $C G B 3$ may be involved in the pathogenesis of HSPCC; however, its precise function warrants further investigation.

MALATl was the first long non-coding RNA prognostic biomarker identified for early-stage NSCLC (39). The deregulation of MALAT1 has been found in various types of cancer, including lung, breast, pancreas, colon, prostate and liver cancer (40). Previous studies have demonstrated that MALAT1 plays a role in cell proliferation, invasion and tumorigenesis (41-43). In addition, the prognostic value of MALAT1 for cancer metastasis of cancer has been reported (44). The expression of MALAT1 was significantly downregulated in HSPCC in this study, which suggested that MALAT1 may be a key regulator of tumorigenesis in HSPCC. In addition, long-term studies are required in order to identify whether $M A L A T 1$ is a predictor for metastasis of HSPCC.

CSDEl (also known as UNR) encodes the RNA-binding protein, which is found to be upregulated in melanoma tumors, and promotes invasion and metastasis (45). The upregulation of $C S D E 1$ has also been identified in breast cancer (46), which suggests that CSDE1 may be involved in tumorigenesis. In the present study, the expression of CSDE1 was downregulated in HSPCC, which may be due to the difference in the type of cancer tissues used. Additionally, this study demonstrated that CSDE1 is under the regulation of hsa-miR-497-5p and hsa-miR-125b-5p (Table VI). The expression of hsa-miR-497-5p has been reported to be significantly decreased in triple-negative breast cancer (47) and to be negatively associated with survival in oropharyngeal squamous cell carcinoma (48). hsa-miR-125b-5p is involved in regulating the proliferation, migration and invasion of tumor cells. The overexpression of hsa-miR-125b-5p has been shown to inhibit cell proliferation, migration and invasion in esophageal squamous cell carcinoma (49). The underlying molecular mechanism of CSDE1 under the regulation of hsa-miR-497-5p and hsa-miR-125b-5p in HPSCC need to be elaborated in future studies.

In differentially expressed miRNAs, we observed that hsa-let-7i-5p, hsa-miR-136-5p and hsa-miR-143-5p were the top 3 upregulated miRNAs in HPSCC. hsa-miR-15a-5p, hsa-miR-2278 and hsa-miR-125a-5p were the top 3 downregulated miRNAs in HPSCC. hsa-let-7i-5p has been shown to be upregulated in triple-negative breast cancer cells, colon cancer cells and non-muscle invasive bladder cancer cells (50-52). The upregulation of hsa-let-7i-5p is associated with an advanced stage, a high grade and therefore, with the progression of clear cell renal cell carcinoma (53). hsa-miR-136-5p has been shown to be significantly upregulated in osteosarcoma and colorectal adenocarcinoma $(54,55)$. hsa-miR-143-5p acts as a strong tumor suppressive factor. It has been confirmed that hsa-miR-143-5p inhibits the proliferation, invasion and migration of cervical cancer cells (56). It has also been shown that hsa-miR-15a-5p acted as a tumor suppressor by silencing the expression of growth promoting oncogenes (57-59). In chronic myeloid leukemia, hsa-miR-15a-5p has been shown to suppress cell growth and metastasis (60). In addition, 
hsa-miR-15a-5p has been shown to be associated with patient survival in lung adenocarcinoma (61). hsa-miR-2278 has been shown to be associated with survival in both rectal and colon cancer (62). hsa-miR-125a-5p is known to act as a tumor suppressor and is downregulated in various malignant tumors, such as laryngeal carcinoma and verrucous carcinoma of the head and neck $(63,64)$. In multiple myeloma cells, the inhibition of hsa-miR-125a-5p has been shown to reduce cell growth, increased cell apoptosis and attenuated cell migration (65). On the whole, these differentially expressed miRNAs may play an important role in the development of HPSCC. In the present study, spliceosome, cell cycle and RNA degradation were significantly enriched signal pathways in HPSCC. Deregulated genes regulated the progression and development of cancer via the cell cycle in various cancer types, including lung adenocarcinoma, colorectal and head and neck cancer (44-46), which indicated that the cell cycle pathway was implicated in the tumorigenesis of HPSCC.

In conclusion, in the present study, we identified 160 DEGs and 79 differentially expressed miRNAs in HPSCC tissues compared to adjacent normal tissues. The top 20 upregulated and downregulated genes in HPSCC were used to construct PPI networks, where SKP1, NONO and ZACN were the hub proteins. DEGs were significantly enriched in the spliceosome, cell cycle and RNA degradation. The present study was the first to investigate the gene and mRNA expression profiles in HPSCC. Our findings may provide the groundwork for the identification of early diagnosis biomarkers for HPSCC and the mechanisms that underlie its pathogenesis, as well as make a contribution for future drug design. However, there are limitations to this study. Firstly, the sample size in the RNA-sequencing was small. Therefore, large numbers of HPSCC tumor samples are needed for further research. Secondly, although deregulated genes, miRNAs and pathways in HPSCC were identified, the biological functions of these genes, miRNAs and pathways were not investigated in this study. In vitro and in vivo experiments are essential for the elucidation of the biological roles of DEGs and differentially expressed miRNAs in HPSCC in future investigations.

\section{Acknowledgements}

Not applicable.

\section{Funding}

No funding was received.

\section{Availability of data and materials}

The datasets used and/or analyzed during the current study are available from the corresponding author on reasonable request.

\section{Authors' contributions}

FW, YF and YL collected the data. FL, WL and XX analyzed and interpreted the data. HL and PG were major contributors in writing the manuscript. HL organized all the data and finally revised the manuscript. PG designed the project. All authors have read and approved the final manuscript.

\section{Ethics approval and consent to participate}

The present study was approved by the Ethics Committee of the First People's Hospital of Jining, and informed written consent was obtained from all patients. Primary tumors and adjacent normal tissues of HPSCC patients were obtained based on the Declaration of Helsinki.

\section{Patient consent for publication}

Not applicable.

\section{Competing interests}

The authors declare that they have no competing interests.

\section{References}

1. Chaturvedi AK, Engels EA,Pfeiffer RM, Hernandez BY, Xiao W, Kim E, Jiang B, Goodman MT, Sibug-Saber M, Cozen W, et al: Human papillomavirus and rising oropharyngeal cancer incidence in the United States. J Clin Oncol 29: 4294-4301, 2011.

2. van Monsjou HS, Balm AJ, van den Brekel MM and Wreesmann VB: Oropharyngeal squamous cell carcinoma: A unique disease on the rise? Oral Oncol 46: 780-785, 2010

3. Hashibe M, Brennan P, Chuang SC, Boccia S, Castellsague X, Chen C, Curado MP, Dal Maso L, Daudt AW, Fabianova E, et al: Interaction between tobacco and alcohol use and the risk of head and neck cancer: Pooled analysis in the International Head and Neck Cancer Epidemiology Consortium. Cancer Epidemiol Biomarkers Prev 18: 541-550, 2009.

4. Chaturvedi AK, Engels EA, Anderson WF and Gillison ML: Incidence trends for human papillomavirus-related and -unrelated oral squamous cell carcinomas in the United States. J Clin Oncol 26: 612-619, 2008.

5. Gillison ML, Alemany L, Snijders PJ, Chaturvedi A Steinberg BM, Schwartz S and Castellsagué X: Human papillomavirus and diseases of the upper airway: Head and neck cancer and respiratory papillomatosis. Vaccine 30 (Suppl 5): F34-F54, 2012.

6. Tartaglia LA and Goeddel DV: Two TNF receptors. Immunol Today 13: 151-153, 1992.

7. Ashkenazi A and Dixit VM: Death receptors: Signaling and modulation. Science 281: 1305-1308, 1998.

8. Ma X, Li X, Lu X, Jia L, Li H and Song Q: Interaction between TNFR1 and TNFR2 dominates the clinicopathologic features of human hypopharyneal carcinoma. Tumour Biol 36: 9421-9429, 2015.

9. Kaira K, Toyoda M, Shimizu A, Imai H, Sakakura K, Nikkuni O, Suzuki M, Iijima M, Asao T and Chikamatsu K: Prognostic significance of GRP78/BiP expression in patients with stage III/IV hypopharyngeal squamous cell carcinoma. Neoplasma 63: 477-483, 2016.

10. Jing P, Sa N, Liu X, Liu X and Xu W: MicroR-140-5p suppresses tumor cell migration and invasion by targeting ADAM10-mediated Notch1 signaling pathway in hypopharyngeal squamous cell carcinoma. Exp Mol Pathol 100: 132-138, 2016.

11. Zhou J, Li M, Yu W, Li W, Wang J, Xiang X, Li G, Pan X and Lei D: AB209630, a long non-coding RNA decreased expression in hypopharyngeal squamous cell carcinoma, influences proliferation, invasion, metastasis, and survival. Oncotarget 7 : 14628-14638, 2016.

12. Qiu X, Chen J, Zhang Z, You Y and Wang Z: Aberrant GRK6 promoter methylation is associated with poor prognosis in hypopharyngeal squamous cell carcinoma. Oncol Rep 35: 1027-1033, 2016.

13. Trapnell C, Pachter L and Salzberg SL: TopHat: Discovering splice junctions with RNA-Seq. Bioinformatics 25: 1105-1111, 2009. 
14. Ghosh S and Chan CK: Analysis of RNA-Seq data using tophat and cufflinks. Methods Mol Biol 1374: 339-361, 2016.

15. Ritchie ME, Phipson B, Wu D, Hu Y, Law CW, Shi W and Smyth GK: Limma powers differential expression analyses for RNA-sequencing and microarray studies. Nucleic Acids Res 43: e47, 2015 .

16. Reiner-Benaim A: FDR control by the $\mathrm{BH}$ procedure for two-sided correlated tests with implications to gene expression data analysis. Biom J 49: 107-126, 2007.

17. Benjamini Y and Hochberg Y: Controlling the false discovery rate-a practical and powerful approach to multiple testing. J Royal Stat Soc 57: 289-300, 1995.

18. Gołębiowski M, Sosnowska A, Puzyn T, Boguś MI, Wieloch W, Włóka E and Stepnowski P: Application of two-way hierarchical cluster analysis for the identification of similarities between the individual lipid fractions of Lucilia sericata. Chem Biodivers 11: 733-748, 2014.

19. Smoot ME, Ono K, Ruscheinski J, Wang PL and Ideker T: Cytoscape 2.8: New features for data integration and network visualization. Bioinformatics 27: 431-432, 2011.

20. Ochs C, Perl Y, Halper M, Geller J and Lomax J: Quality assurance of the gene ontology using abstraction networks. J Bioinform Comput Biol 14: 1642001, 2016.

21. Kanehisa M, Sato Y, Kawashima M, Furumichi M and Tanabe M: KEGG as a reference resource for gene and protein annotation. Nucleic Acids Res 44: D457-D462, 2016.

22. Chatr-Aryamontri A, Breitkreutz BJ, Oughtred R, Boucher L, Heinicke S, Chen D, Stark C, Breitkreutz A, Kolas N, O'Donnell L, et al: The BioGRID interaction database: 2015 update. Nucleic Acids Res 43: D470-D478, 2015.

23. Shannon P, Markiel A, Ozier O, Baliga NS, Wang JT, Ramage D, Amin N, Schwikowski B and Ideker T: Cytoscape: A software environment for integrated models of biomolecular interaction networks. Genome Res 13: 2498-2504, 2003.

24. Keaton MA: Morgan DO: The cell cycle: Principles of control (Primers in Biology). Cell Division 2: 27, 2007.

25. Liu YQ, Wang XL, Cheng X, Lu YZ, Wang GZ, Li XC, Zhang J, Wen ZS, Huang ZL, Gao QL, et al: Skp1 in lung cancer: Clinical significance and therapeutic efficacy of its small molecule inhibitors. Oncotarget 6: 34953-34967, 2015.

26. Xu M, Yang X, Zhao J, Zhang J, Zhang S, Huang H, Liu Y and Liu J: High expression of Cullin1 indicates poor prognosis for NSCLC patients. Pathol Res Pract 210: 397-401, 2014

27. Houtani T, Munemoto Y, Kase M, Sakuma S, Tsutsumi T and Sugimoto T: Cloning and expression of ligand-gated ion-channel receptor L2 in central nervous system. Biochem Biophys Res Commun 335: 277-285, 2005.

28. Ma D, Shield JP, Dean W, Leclerc I, Knauf C, Burcelin R Ré, Rutter GA and Kelsey G: Impaired glucose homeostasis in transgenic mice expressing the human transient neonatal diabetes mellitus locus, TNDM. J Clin Invest 114: 339-348, 2004.

29. Zhu Z, Zhao X, Zhao L, Yang H, Liu L, Li J, Wu J, Yang F, Huang $G$ and Liu J: p54 5 nrb/NONO regulates lipid metabolism and breast cancer growth through SREBP-1A. Oncogene 35: $1399-1410,2016$

30. Yang P, Chen T, Xu Z, Zhu H, Wang J and He Z: Long noncoding RNA GAPLINC promotes invasion in colorectal cancer by targeting SNAI2 through binding with PSF and NONO. Oncotarget 7: 42183-42194, 2016.

31. Vilming Elgaaen B, Olstad OK, Haug KB, Brusletto B, Sandvik L, Staff AC, Gautvik KM and Davidson B: Global miRNA expression analysis of serous and clear cell ovarian carcinomas identifies differentially expressed miRNAs including miR-200c-3p as a prognostic marker. BMC cancer 14: 80, 2014.

32. Chandra V, Kim JJ, Mittal B and Rai R: MicroRNA aberrations: An emerging field for gallbladder cancer management. World J Gastroenterol 22: 1787-1799, 2016

33. Kubiczak M, Walkowiak GP, Nowak-Markwitz E and Jankowska A: Human chorionic gonadotropin beta subunit genes $C G B 1$ and $C G B 2$ are transcriptionally active in ovarian cancer. Int J Mol Sci 14: 12650-12660, 2013.

34. Hotakainen K, Lintula S, Jarvinen R, Paju A, Stenman J, Rintala E and Stenman UH: Overexpression of human chorionic gonadotropin beta genes 3,5 and 8 in tumor tissue and urinary cells of bladder cancer patients. Tumour Biol 28: 52-56, 2007.

35. Hotakainen K, Lintula S, Ljungberg B, Finne P, Paju A, Stenman UH and Stenman J: Expression of human chorionic gonadotropin beta-subunit type I genes predicts adverse outcome in renal cell carcinoma. J Mol Diagn 8: 598-603, 2006.
36. Iles RK: Ectopic hCGbeta expression by epithelial cancer: Malignant behaviour, metastasis and inhibition of tumor cell apoptosis. Mol Cell Endocrinol 260-262: 264-270, 2007.

37. Iles RK, Delves PJ and Butler SA: Does hCG or hCG $\beta$ play a role in cancer cell biology? Mol Cell Endocrinol 329: 62-70, 2010.

38. Hotakainen K, Ljungberg B, Haglund C, Nordling S, Paju A and Stenman UH: Expression of the free beta-subunit of human chorionic gonadotropin in renal cell carcinoma: Prognostic study on tissue and serum. Int J Cancer 104: 631-635, 2003.

39. Wu Y, Lu W, Xu J, Shi Y, Zhang H and Xia D: Prognostic value of long non-coding RNA MALAT1 in cancer patients. Tumour Biol 37: 897-903, 2016.

40. Lin R, Maeda S, Liu C, Karin M and Edgington TS: A large noncoding RNA is a marker for murine hepatocellular carcinomas and a spectrum of human carcinomas. Oncogene 26: 851-858, 2007

41. Yang MH, Hu ZY, Xu C, Xie LY, Wang XY, Chen SY and Li ZG: MALAT1 promotes colorectal cancer cell proliferation/migration/invasion via PRKA kinase anchor protein 9. Biochim Biophys Acta 1852: 166-174, 2015.

42. Wu XS, Wang XA, Wu WG, Hu YP, Li ML, Ding Q, Weng H, Shu YJ, Liu TY, Jiang L, et al: MALAT1 promotes the proliferation and metastasis of gallbladder cancer cells by activating the ERK/MAPK pathway. Cancer Biol Ther 15: 806-814, 2014.

43. Ying L, Chen Q, Wang Y, Zhou Z, Huang Y and Qiu F: Upregulated MALAT-1 contributes to bladder cancer cell migration by inducing epithelial-to-mesenchymal transition. Mol Biosyst 8: 2289-2294, 2012.

44. Tano K and Akimitsu N: Long non-coding RNAs in cancer progression. Front Genet 3: 219, 2012.

45. Wurth L, Papasaikas P, Olmeda D, Bley N, Calvo GT, Guerrero S, Cerezo-Wallis D, Martinez-Useros J, García-Fernández M, Hüttelmaier S, et al: UNR/CSDE1 drives a post-transcriptional program to promote melanoma invasion and metastasis. Cancer Cell 30: 694-707, 2016.

46. Fang H, Yue X, Li X and Taylor JS: Identification and characterization of high affinity antisense PNAs for the human unr (upstream of N-ras) mRNA which is uniquely overexpressed in MCF-7 breast cancer cells. Nucleic Acids Res 33: 6700-6711, 2005.

47. Chang YY, Kuo WH, Hung JH, Lee CY, Lee YH, Chang YC, Lin WC, Shen CY, Huang CS, Hsieh FJ, et al: Deregulated microRNAs in triple-negative breast cancer revealed by deep sequencing. Mol Cancer 14: 36, 2015.

48. Wong N, Khwaja SS, Baker CM, Gay HA, Thorstad WL, Daly MD, Lewis JS Jr and Wang X: Prognostic microRNA signatures derived from The Cancer Genome Atlas for head and neck squamous cell carcinomas. Cancer Med 5: 1619-1628, 2016.

49. Mei LL, Wang WJ, Qiu YT, Xie XF, Bai J and Shi ZZ: miR-125b-5p functions as a tumor suppressor gene partially by regulating HMGA2 in esophageal squamous cell carcinoma. PLoS One 12: e0185636, 2017.

50. Qattan A, Intabli H, Alkhayal W, Eltabache C, Tweigieri T and Amer SB: Robust expression of tumor suppressor miRNA's let-7 and miR-195 detected in plasma of Saudi female breast cancer patients. BMC Cancer 17: 799, 2017.

51. Choo KB, Soon YL, Nguyen PN, Hiew MS and Huang CJ: MicroRNA-5p and -3p co-expression and cross-targeting in colon cancer cells. J Biomed Sci 21: 95, 2014.

52. Armstrong DA, Green BB, Seigne JD, Schned AR and Marsit CJ: MicroR NA molecular profiling from matched tumor and bio-fluids in bladder cancer. Mol Cancer 14: 194, 2015.

53. Gowrishankar B, Ibragimova I, Zhou Y, Slifker MJ, Devarajan K, Al-Saleem T, Uzzo RG and Cairns P: MicroRNA expression signatures of stage, grade, and progression in clear cell RCC. Cancer Biol Ther 15: 329-341, 2014

54. Lauvrak SU, Munthe E, Kresse SH, Stratford EW, Namløs HM, Meza-Zepeda LA and Myklebost O: Functional characterisation of osteosarcoma cell lines and identification of mRNAs and miRNAs associated with aggressive cancer phenotypes. Br J Cancer 109: 2228-2236, 2013.

55. Zheng G, Du L, Yang X, Zhang X, Wang L, Yang Y, Li J and Wang C: Serum microRNA panel as biomarkers for early diagnosis of colorectal adenocarcinoma. Br J Cancer 111: 1985-1992, 2014.

56. Jin X, Chen X, Hu Y, Ying F, Zou R, Lin F, Shi Z, Zhu X, Yan X, Li S and Zhu H: LncRNA-TCONS 00026907 is involved in the progression and prognosis of cervical cancer through inhibiting miR-143-5p. Cancer Med 6: 1409-1423, 2017. 
57. Calin GA, Cimmino A, Fabbri M, Ferracin M, Wojcik SE Shimizu M, Taccioli C, Zanesi N, Garzon R, Aqeilan RI, et al: MiR-15a and miR-16-1 cluster functions in human leukemia. Proc Natl Acad Sci USA 105: 5166-5171, 2008.

58. Pekarsky Y and Croce CM: Role of miR-15/16 in CLL. Cell Death Differ 22: 6-11, 2015.

59. Huang E, Liu R and Chu Y: miRNA-15a/16: As tumor suppressors and more. Future Oncol 11: 2351-2363, 2015.

60. Chen D, Wu D, Shao K, Ye B, Huang J and Gao Y: MiR-15a-5p negatively regulates cell survival and metastasis by targeting CXCL10 in chronic myeloid leukemia. Am J Transl Res 9: 4308-4316, 2017

61. Yanaihara N, Caplen N, Bowman E, Seike M, Kumamoto K, Yi M, Stephens RM, Okamoto A, Yokota J, Tanaka T, et al: Unique microRNA molecular profiles in lung cancer diagnosis and prognosis. Cancer Cell 9: 189-198, 2006.

62. Slattery ML, Pellatt AJ, Lee FY, Herrick JS, Samowitz WS Stevens JR, Wolff RK and Mullany LE: Infrequently expressed miRNAs influence survival after diagnosis with colorectal cancer. Oncotarget 8: 83845-83859, 2017.
63. Yao XD, Li P and Wang JS: MicroRNA differential expression spectrum and microRNA-125a-5p inhibition of laryngeal cancer cell proliferation. Exp Ther Med 14: 1699-1705, 2017.

64. Odar K, Boštjančič E, Gale N, Glavač D and Zidar N: Differential expression of microRNAs $m i R-21, m i R-31, m i R-203$, $m i R-125 a-5 p$ and $m i R-125 b$ and proteins PTEN and p63 in verrucous carcinoma of the head and neck. Histopathology 61: 257-265, 2012.

65. Leotta M, Biamonte L, Raimondi L, Ronchetti D, Di Martino MT, Botta C, Leone E, Pitari MR, Neri A, Giordano A, et al: A p53-dependent tumor suppressor network is induced by selective miR-125a-5p inhibition in multiple myeloma cells. J Cell Physiol 229: 2106-2116, 2014

This work is licensed under a Creative Commons Attribution-NonCommercial-NoDerivatives 4.0 International (CC BY-NC-ND 4.0) License. 